\title{
rs10046 Polymorphism of CYP19A1 Gene related to Sex Hormone in Female with Acromegaly Iraqi patients
}

\author{
Iqbal H. Dhefer ${ }^{1 *}$, Najwa Sh Ahmed ${ }^{2}$, Salma Abdul-rudha Abbas ${ }^{1}$ \\ ${ }^{I}$ Nursing Department, AL-Suwaira Technical Institute ,Middle Technical University \\ ${ }^{2}$ Biotechnology Research, Molecular, and Biotechnology Laboratory, AL-Nahrain University, Baghdad, Iraq. \\ ${ }^{3}$ Mustansiriya University, College of Science, Baghdad, Iraq.
}

*Corresponding Author: Iqbal H. Dhefer, Nursing Department, AL-Suwaira Technical Institute, Middle Technical University Iraq.

\begin{abstract}
Testosterone and estradiol have been considered to be male and female sex hormones, respectively. However, testosterone, also plays a critical role in female sexual function. There is an evidence showing that sex hormone is associated with polymorphisms in the 3' untranslated region $T>C$ rs 10046 (SNPS) single nucleotide polymorphisms in CYP19A1 gene. Whole blood genomic DNA was extracted to perform genotyping analysis and rs10046 SNP in the CYP19A1gene by using PCR-restriction fragment length polymorphism technique. Serum testosterone and estradiol levels were determined by using method of enzyme immunoassay competition with a final fluorescent detection. Results show that in estradiol level is significantly decreased while testosterone level is significantly increased in female acromegaly patients when contrasted with healthy control groups in both sexes $(p \leq 0.01)$ and showed high significance in TT,CC and TC alleles when contrasted with healthy control groups ( $p \leq 0.01)$.
\end{abstract}

Keywords: Testosterone, estradiol, acromegaly, rs10046, TT allele, CC allele.

\section{INTRODUCTION}

Acromegaly is an uncommon disease which progresses slowly and results from a chronical excess of growth hormone $(\mathrm{GH})$, and connected to noticeable morbidity and increased mortality (Abreu et al., 2016). The following increase in insulin-like growth facter1 (IGF-1) is accountable for greatest systemic complications and for the clinical characteristics (comprise arthralgia, soft tissue changes, visceromegaly, and comorbidities comprise, type 2 diabetes, hypertension , carpal tunnel syndrome, and sleep apnea) related with increased mortality. The medical diagnosis, depends on symptoms associated to presence of the mass pituitary gland or excess of $\mathrm{GH}$, is often belated several years due to the slow development of the disease (Capatina and Wass, 2015). Testicles is produce the testosterone hormone that is accountable for the suitable progress of sexual features of male. Testosterone is too important for keeping bone growth, muscle bulk, sexual function, , a sense of well-being and tolerable levels of red blood cells (Xing et al., 2017). The adrenal gland, ovaries , and likewise the placenta through pregnancy produce the estradiol is female sex hormone that is the most essential hormone through a female's generative years, also is needed for sexual function and generative also having an effect on the health of a different tissues and organs ((Huang et al., 2015). The cytochrome p450 gene (CYP19A1), found on 15q21.2 chromosome, which encodes for the aromatase enzyme, and catalyzes the last step in biosynthesis of estrogen and metabolism that converting testosterone to estradiol (Chen et al., 2008). Aromatase(CYP19A1) expression is controlled via distinct tissue specific promoters in (he bone, placenta, vascular endothelium, breast, adipose tissue, ovary, and brain causing estrogen production in local extragonadal and systemic gonadalovarian. CYP19A1 is located at chromosome 15 and spans about $123 \mathrm{~kb}$ in length via criteria of other cytochrome genes that's encoding the CYP19 is unusually significant since it is above $50 \mathrm{kbp}$.The gene has a number of alternate non-coding first exons that regulate tissue specific expression and nine coding exons (Corbin et al., 1988). The whole aromatase gene extents about $123 \mathrm{~kb}$ (Verma et al., 2012) . Thirty -kb 3'-end of the gene embraces nine exons that encode the aromatase enzyme protein, and $93-\mathrm{kbp}$ at $5^{\prime}$-flanking area of this gene embraces one-off (5'-untranslated) first exon and several of tissue specific promoters, this $1^{\text {st }}$ exon is spliced onto a usual splice crossroads like that each 

patients

promoter-specific mRNA fragment encodes the same aromatase enzyme protein (Demura et al., 2011). This gene, mutations may occur in whichever elevate or decline aromatase enzyme activity the related phenotypes propose that estradiol functions both like sex steroid hormone and in differentiation or growth. Previous studies examining the relations of selected CYP19Al variants, including the polymorphism in the 3' untranslated region C>T rs10046 SNP in CYP19A1 are correlated with estradiol levels; specially rs 10046, (Chen et al., 2008).

\section{Patients AND Methods}

Sixty female (age 30-50 years) were recorded in this study, thirty patients with acromegaly who have be attended at the national diabetes center, Baghdad, Iraq from December 2015 to June 2016 and thirty healthy individual with matches as a control healthy group. All patients were diagnosed by physicians. Blood was collected; each blood sample was split into two fractions. The first fraction was conveyed into tube containing ethylene diamine tetraacetic acid disodium salt (EDTA) used for whole blood genotyping analysis. The other fraction was separated in plain polyethylene test tube, left at room temperature to clot then the tube was centrifuged (at $704 \times \mathrm{g}$ for 10 minutes), and the sera were separated.

Testosterone and estradiol levels were determined using VIDAS ${ }^{\circledR}$ kit obtained from Biomerux , using the ELFA method, at $450 \mathrm{~nm}$, the conjugated enzyme that catalyze the substrate hydrolysis hooked on the fluorescent yield and the fluorescence intensity was inversely proportionate to the concentration of the sex hormone (Testosterone or estradiol) present in the sample. The outcomes were automatically designed via the device in the relative to the calibration curve saved in memory at the end of the assay and then printed out .

Optimization of PCR reactions was achieved after many endeavors to reveal the best annealing temperature and both primer and DNA concentrations .By useing maximum PCR premix kit(i-Taq), and PCR, since CYP19 rs 10046 polymorphisms were designed for amplification a PCR method via using two primers (Wang et al., 2014). Briefly, DNA was augmented by primers that, forward (5'TAGAGAAGGCTGGTCAGTGCC-3' and reverse 5'-CTCT GG TGTGAACAGGAGCA-3'), then followed by digestion with restriction enzyme Nco I. Primers set was supplied by Integrated DNA Technologies company Canada (IDT). PCR reaction was done in $25 \mu \mathrm{l}$ of a reaction mixture including 1.5 $\mu \mathrm{L}$ of DNA, five $\mu \mathrm{L}$ of PreMix Master Mix, $1 \mu \mathrm{L}$ of (10 Pmol $\backslash \mu \mathrm{l})$ of each primer, 16.5 $\mu \mathrm{L}$ of distilled water. Amplification program was single cycle at $94^{\circ} \mathrm{C}$ for three minute, 35 cycles at $94^{\circ} \mathrm{C}$ to 45 second, $60^{\circ} \mathrm{C}$ for 45 second and $72^{\circ} \mathrm{C}$ for 45 second, one cycle at $72^{\circ} \mathrm{C}$ to 10 minute. The amplified yield was put in $2 \%$ agarose gel electrophoresis with $1.0 \mu \mathrm{L}$ red stain and $5 \mu \mathrm{L}$ ladder, and visualized under UV (Agarose Gel Electrophoresis System MGu-502T-pk, USA) after Red safe staining.

To identify the polymorphism of $r s 10046$ gene in the 3 ' untranslated region $\mathrm{T}>\mathrm{C}$ in products of $\mathrm{PCR}$ was determined by PCR- RFLP, PCR reaction was conducted in $10 \mu \mathrm{l}$ of a reaction mixture containing $5 \mu \mathrm{L}$ of PCR product, one $\mu \mathrm{L}$ of enzyme Nco I (500U), $0.2 \mu \mathrm{L}$ of BSA and $3.8 \mu \mathrm{L}$ of Buffer. Then the reaction mixture was mixed and then spined down and incubated at $\quad 37^{\circ} \mathrm{C}$ for 20 hours incubation. After that, five $\mu \mathrm{L}$ of the reaction combination were put on $1.5 \%$ agarose gel stained with $2.0 \mu \mathrm{L}$ of red stain and $5 \mu \mathrm{L}$ ladder and visualized under UV (Agarose Gel Electrophoresis System MGu-502T-pk, USA) after red safe staining.

\section{Statistical ANALYSIS}

Statistical analysis was done utilizing Microsoft Office (SPSS vs. 19) which include the following (mean \pm stranded deviation-test, correlation coefficient; P-value $\leq 0.01$ was significant. In all studied groups the total prescient values for the outcomes were performed according to biostatistics via Daniel (1987), and the statistical analysis system- SAS was utilized. The Pearson x2 criterion ( $\mathrm{p} \leq$ 0.01), was employed to compare the polymorphisms frequencies of CYP19A1 gene between the groups.

\section{RESUltS AND DiSCUSSION}

Figure (1) showed the mean $\pm \mathrm{SD}$ of testosterone hormone levels expressed as $\mathrm{ng} / \mathrm{mL}$ and estradiol hormone levels expressed as $\mathrm{Pg} / \mathrm{mL}$ in the sera of female for both control and active acromegaly patients. 

patients

Ahighly significant increase in testosterone levels of female with active acromegaly patients was recorded. There was ahighly significant decrease in estradiol hormone levels in female with active acromegaly patients when compared with control group ( $\mathrm{p} \leq 0.01)$. There was Asignificant increase in Test./E2 ratio of female with active acromegaly patients when compared with male and female control group.
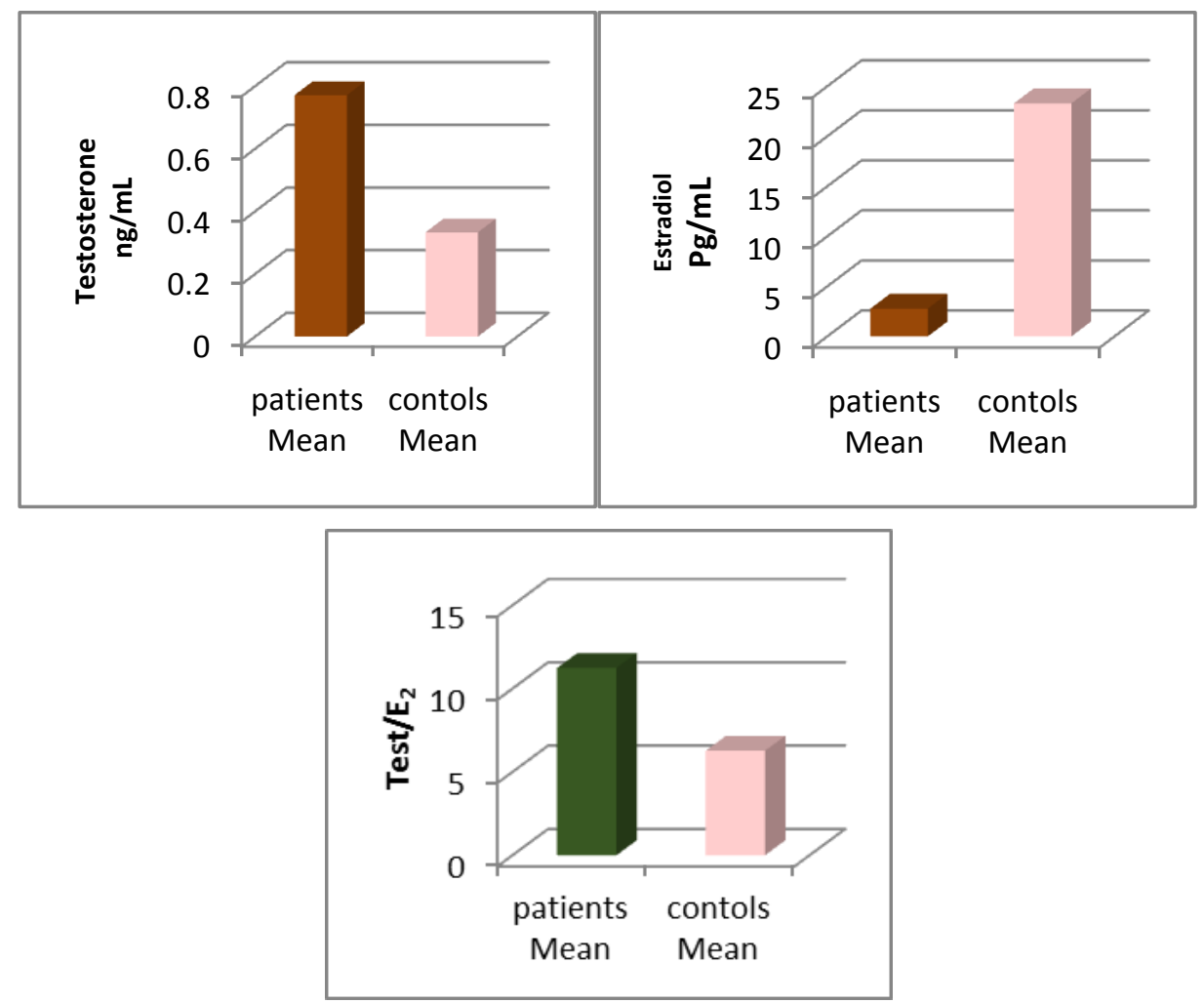

Figure1. Sex hormone levels in studied groups.

The TT allele was referred by $190 \mathrm{bp}$ single band, while the CC allele was referred by two bands 169 and $21 \mathrm{bp}$, and the TC allele was referred by the existence of three bands 21, 169 and $190 \mathrm{bp}$ )as shown in Figure(2).

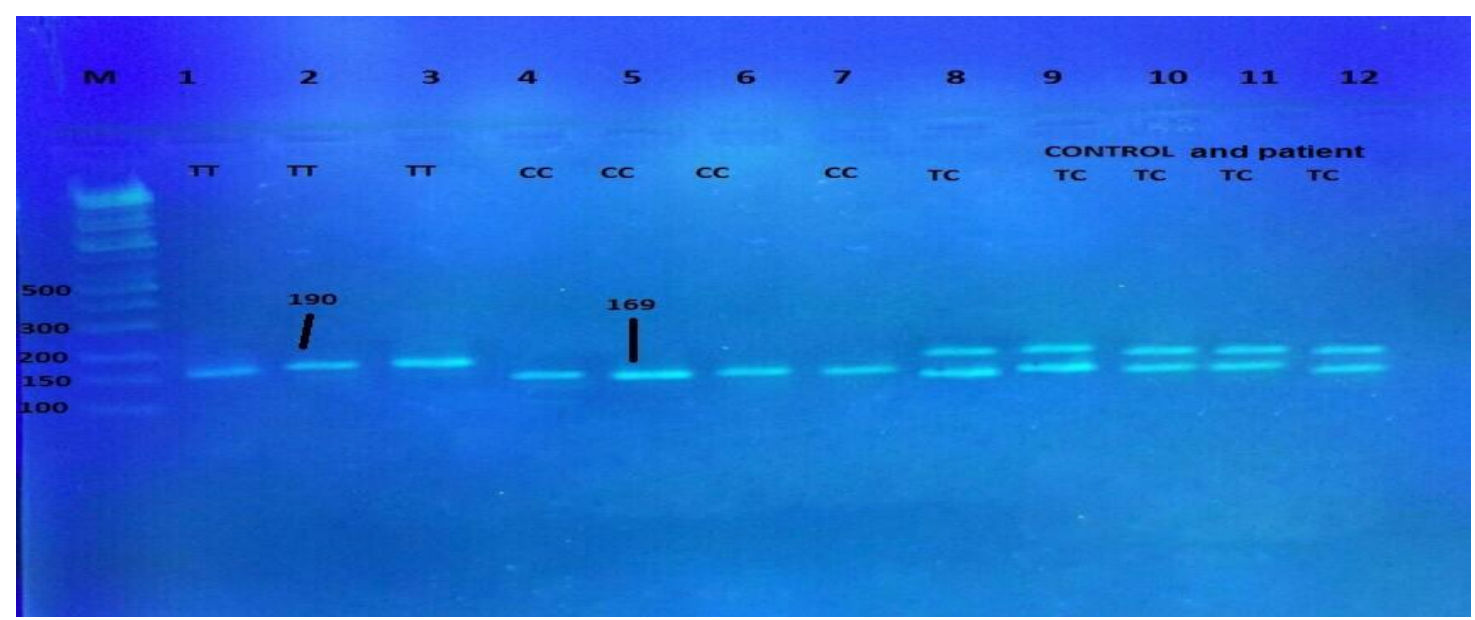

Figure2. Genotyping of CYP19 rs10046: T>C by RFLP-PCR in control and patient samples: lane M, 500bp DNA ladder; lane 1-3, TT genotype (190bp); lane 4-7, CC genotype (169,21bp)); lane 8-12, TC genotype (190, 169and $21 \mathrm{bp}$ )

Table (1) summarizes the positive results of RFLP allele in male and female in patients and control. Nine female patients out of 30 female patients exhibited TT allele which not present in female control .These exhibited a high significance in TT allele when compared with female control group $(\mathrm{p} \leq 0.01)$.While 9 female patients from 30 female patients confer $\mathrm{CC}$ allele $(27.27 \%)$ and not exhibited in female control. Results showed that there was highly significant in CC allele when 
rs10046 Polymorphism of CYP19A1 Gene related to Sex Hormone in Female with Acromegaly Iraqi patients

compared with male control group $(\mathrm{p} \leq 0.01)$. While 12 female patients out of 30 female patients confer TC allele (80\%) and all 30 female control having TC allele(100\%) these results showed that there was non significantly differences in TC allele when compared with female control group $(\mathrm{p} \leq 0.01)$.

Table1. Results of RFLP in female patients and controls sample.

\begin{tabular}{|c|c|c|c|c|}
\hline Group & $\begin{array}{c}\text { Sum of positive } \\
\text { results of allele TT } \\
(\mathbf{1 9 0}\end{array}$ & $\begin{array}{c}\text { Sum of positive } \\
\text { results of allele } \\
\text { CC(169,21) }\end{array}$ & $\begin{array}{c}\text { Sum of positive results of } \\
\text { allele TC(190,169,21) }\end{array}$ & P-value \\
\hline Patients & 9 & 9 & $\mathbf{1 2}$ & $0.0001^{*}$ \\
\hline Control & 0 & 0 & 30 & $0.0001^{*}$ \\
\hline
\end{tabular}

* Significant difference : $(p \leq 0.01)$

It is concluded that the testosterone and estradiol measurement in serum in acromegaly patients and healthy controls are related to their alleles. The results detected a significant elevation in testosterone hormone and decrease in estradiol hormone levels in acromegaly in patients carrying (TC) genotype of rs10046 compared to individual that had the same genotypes in control group $(p \leq 0.05)$. Whereas other genotypes were not found in control group and so testosterone and estrogen hormones levels shows highly significantly difference among the two groups, Table (2 and 3 ).

Table2. Comparison of testosterone levels between acromegaly and control according to Genotypes.

\begin{tabular}{|c|c|c|c|c|c|}
\hline \multirow{3}{*}{ SNP } & \multirow{2}{*}{$\begin{array}{c}\text { Allele } \\
\text { Genotype }\end{array}$} & \multicolumn{3}{|c|}{$\begin{array}{c}\text { Testosterone (ng/mL) } \\
\text { Mean } \pm \text { SD }\end{array}$} & \multirow{2}{*}{$p$ - value } \\
\cline { 3 - 6 } & & gender & Patient & Control & \\
\hline \multirow{3}{*}{ rs10046 } & \multirow{2}{*}{ TT } & $\mathrm{M}$ & $15.466 \pm 6.823$ & - & $0.000^{*}$ \\
\cline { 3 - 6 } & & $\mathrm{F}$ & $0.136 \pm 0.055$ & - & $0.000^{*}$ \\
\cline { 2 - 6 } & $\mathrm{CC}$ & $\mathrm{M}$ & $14.090 \pm 2.161$ & - & $0.000^{* *}$ \\
\cline { 2 - 6 } & & $\mathrm{F}$ & $0.137 \pm 0.046$ & - & $0.005^{*}$ \\
\cline { 2 - 6 } & $\mathrm{TC}$ & $\mathrm{M}$ & $15.466 \pm 6.823$ & $4.400 \pm 2.120$ & $0.001^{*}$ \\
\cline { 2 - 6 } & & $\mathrm{F}$ & $0.277 \pm 0.150$ & $0.183 \pm 0.063$ & $0.000^{*}$ \\
\hline
\end{tabular}

* Significant difference : $(p \leq 0.05)$.

Table3. Association in estradiol hormone between acromegaly and control according to Genotypes.

\begin{tabular}{|c|c|c|c|c|c|}
\hline \multirow{3}{*}{ SNP } & $\begin{array}{c}\text { Allele } \\
\text { Genotype }\end{array}$ & \multicolumn{3}{|c|}{$\begin{array}{c}\text { Estrogen (pg/mL) } \\
\text { Mean } \pm \text { SD }\end{array}$} & \multirow{2}{*}{$p$ - value } \\
\cline { 3 - 6 } & & gender & Patient & Control & \\
\hline \multirow{4}{*}{ rs10046 } & \multirow{2}{*}{ TT } & $\mathrm{M}$ & $20.167 \pm 9.008$ & - & $0.005^{*}$ \\
\cline { 3 - 6 } & & $\mathrm{F}$ & $21.70 \pm 10.895$ & - & $0.000^{*}$ \\
\cline { 2 - 6 } & $\mathrm{CC}$ & $\mathrm{M}$ & $25.765 \pm 11.801$ & - & $0.000^{*}$ \\
\cline { 2 - 6 } & & $\mathrm{F}$ & $19.622 \pm 5.057$ & - & $0.000^{*}$ \\
\cline { 2 - 6 } & $\mathrm{TC}$ & $\mathrm{M}$ & $20.100 \pm 9.112$ & $63.760 \pm 27.352$ & $0.000^{*}$ \\
\cline { 2 - 6 } & & $\mathrm{F}$ & $18.825 \pm 8.762$ & $52.235 \pm 24.970$ & $0.000^{*}$ \\
\hline
\end{tabular}

* Significant difference at : $(p \leq 0.05)$.

This is a pioneer study investigating the correlation of CYP19A1 gene $r$ s 10046 polymorphisms with the acromegaly. We confined the study to the Iraqi people in the areas of Baghdad city to keep up genetic homogeneity between the people. Furthermore to avert the confusing effects of environmental factors and interracial variations of genetic backgrounds, like living behavior. The current study investigated the aromatase activity and polymorphism of CYP19A1 genes among 30 apparently female healthy and 30 active acromegaly female patients from different regions of Baghdad. The relationship between CYP19A1 gene rs 10046 polymorphism and various factors was studied. There is an association between $C Y P 19$ gene polymorphism $r s 10046$ with testosterone and estradiol hormones which is related to acromegaly in Iraqi patients. There was significant association between levels of sex hormones with genotype of rs10046 polymorphisms compared to individuals have the same genotypes in control group. The correlation between single nucleotide polymorphisms (SNPs) of this gene and this result provides convincing proof that (CYP19A1) genetic variation is a predictive factor to acromegaly in Iraqi population. These results are in agreement with the study of Link et al. (1986) and Leporati et al. (2015) who found that the pubertal IGF-1 and growth hormone flows seem 
secondary to pubertal rises in levels of testosterone .Alternatively, the growth hormone reduction of elder men is related with age- associated reductions in androgen levels, and testosterone replacement which increases GH levels in healthy old men. Also the testosterone has been appeared to stimulate the somatotropic axis in young male; this result was reliant on aromatization because of the stimulatory influence blunted following selective estrogen modulators management (Veldhuis et al., 2009).

This study demonstrated significant reduction in estradiol hormone and increase in testosterone hormone levels among acromegalic patients compared to control group which in line with study of Selek et al. (2015) who reported there an increase in LH levels causing a secondary increase in testosterone production which in turn increases growth hormone secretion after aromatization. Also they found an elevated expression of aromatase in growth hormone pituitary adenomas secreting, suggestive of aromatization. Expression of estrogen receptor-alpha was depress in the group of acromegaly compared with usual pituitary tissue. Estradiol is created locally via aromatization may be included in the activation of the mitotic activity in the anterior pituitary (Barrado et al., 2014). So, increased aromatase expression may cause the tumors growth in pituitary. In contrast, the other study has revealed that greater expression of aromatase in tumor tissues is associated with enhance prognosis (Adelman et al., 2013).

Aromatase enzyme may influence both differentiation in cellular and tumor creation. Results suggest that aromatase inhibitors may be another treatment modalities, particularly in acromegaly patients. Though, the stimulatory influence of testosterone on the growth hormone axis may be arbitrated at the hypothalamic level, mainly by promoting growth hormone releasing hormone (GHRH), which influences may also be arbitrated directly by testosterone by androgen receptors or throughout aromatization of estradiol (Bondanelli et al., 2003). In latest years the developing importance of estradiol signaling in males in addition to its main role in the female generative system has been emphasized. Aromatase enzyme is the key enzyme use for synthesis of estradiol from testosterone and is accountable for controlling the androgen/estrogen ratio, aromatase gene expression inhibition can be attained in different ways and is significant for the treatment of numerous estrogen-dependent diseases, such as gynecomastia/breast cancer in males ,breast cancer in females or for nontumorigenic conditions such as precocious puberty and the initiation of ovulation. The aromatase inhibition could also help as a tool for examining the estradiol role during adulthood or development (Barrado et al., 2014). The most important reason for this result in the present study and others, is inhibiting aromatase formation will also seemingly rise testosterone levels because of reduce testosterone which will be converted into estradiol (Cook et al., 2004). Test. /E2 ratio is organized by intracellular and aromatase activity which seems to be fundamental for ovulation induction and oocytes apoptosis (Mitwally and Casper, 2003 ). Clinical studies related that when estradiol lack significant in men, estradiol actions and its requirement in males also has turned into an accepted idea (Rochira et al., 2015).

A important correlation of SNPs in aromatase and haplotypes with levels of circulating estradiol between postmenopausal female has been reported by Glubb et al. (2017). Existence of the C allele ( rs 10046 SNP )is related to a decreased levels of estradiol, the authors showed that measurements at different times, levels of estradiol in the same personal recorded (50\%) of the variance in the levels of estradiol which is fundamentally random fluctuation depending on this suggestion and on mean values of estradiol related with the rs10046 TT plus TC alleles (Zins et al., 2014).The absence of estrogen synthesis due to complete aromatase activity deficiency resulted in an increase in the level of essential FSH (Paul and Sudaniradoss, 2016) .Thist phenotypic change may be affected by modifying factors like variability in coregulators, non-classic pathways of estrogen synthesis, or differences in androgen responsiveness that propose an significant modulatory function for the aromatase enzyme in metabolic function and endocrine within the broader populace (Lin et al., 2007). One might concluded from the current results that the rs 10046 polymorphism donates to circulating estradiol levels.

In the current work, we suggest once this correlation is confirmed by the biological importance of testosterone and estradiol levels and illustrated across functional analyses, the $r s 10046$ polymorphism could be a probable goal for the early treatment and prevention of acromegaly. Additionly in this work provides decisive evidence that genetic variation in CYP19Al is a predictive factor for acromegaly in Iraqi population. 

patients

\section{CONCLUSION}

This is the first study in the world investigating the correlation of CYP19A1 gene rs 10046 polymorphism with the receptivity to acromegaly TT and CC genotypes tended to be related with an elevated acromegaly risk and found the relationship between alleles of rs 10046 SNP and aromatase testosterone and estradiol levels. The correlation between single nucleotide polymorphisms (SNPs) of this gene and these analytics provide decisive evidence that genetic variation in CYP19A1 is a predictive factor for acromegaly in Iraqi population. The polymorphism of CYP19A1 gene can be considered as a new diagnostic method instead of medical imaging and medical examination that can result in some problems for the patients for the purpose of diagnosis.

\section{ACKNOWLEDGEMENT}

We thanks people who donated their blood samples for the approval of genetic analysis.

\section{REFERENCES}

[1] Abreu A., TovarA.P., Castellanos R., ValenzuelaA., MilenaC., Giraldo G., Pinedo A. C., et al. (2016). Challenges in the diagnosis and management of acromegaly: a focus on comorbidities. Pituitary, 19(4): 448-457.

[2] Capatina C. and Wass J.A. (2015) . Acromegaly. Journal of Endocrinology, 226(2): 141-160.

[3] Xing Y., Liu X., Yan M., Chen T., Lu F., Xu B., Gong Y., et al .(2017). Impact of nonsteroidal aromatase inhibitors on steroid profile in a Chinese population. Medicine (Baltimore), 96(28): 7411-7418.

[4] Huang Y. H., Shen L., Cai A. H. and Liang X. F. (2015). Effects of conservative laparoscopic endometrial cystectomy and use of kidney-reinforcing and blood activating traditional Chinese medicine on ovarian functions. Genetics and Molecular Research ,14(1):645-650.

[5] Chen C., Sakoda L.C., Doherty J.A., Loomis M.M., Fish S. and Ray R.M. (2008). Genetic variation in CYP19A1 and risk of breast cancer and fibrocystic breast conditions among women in Shanghai, China. Cancer Epidemiol Biomarkers Prev, 17(12):3457-3466.

[6] Corbin C. J., Graham L. S., McPhaul M., Mason J.I., Mendelson C.R. and Simpson E.R.(1988). Isolation of a full-length cDNA insert encoding human aromatase system cytochrome P-450 and its expression in non-steroidogenic cells. Proceedings of the National Academy of Science, 85(23):8948-8952.

[7] Verma N., Jain V., Birla S., Jain R. and Sharma A.(2012). Growth and hormonal profile from birth to adolescence of a girl with aromatase deficiency. Journal of Pediatric Endocrinology and Metabolism, 25(11-12):1185-1190.

[8] Demura M., Demura Y., Ameshima S., Ishizaki T., Sasaki M., Miyamori I., Yamagishi M., Takeda Y. , and Bulun S. E. (2011). Changes in Aromatase (CYP19) Gene Promoter Usage in Non-Small Cell Lung Cancer. Lung Cancer ,73(3): 289-293.

[9] Wang L., Lu X., Wang D., Qu W., Li W., Xu X., Huang Q. et al. (2014). CYP19 gene variant confers susceptibility to endometriosis-associated infertility in Chinese women. Experimental \& Molecular Medicine ,46(6): 103-110.

[10] Link K., Blizzard R.M., Evans W.S., Kaiser D.L., Parker M.W. and Rogol A.D.(1986). The effect of androgens on pulsatile release and the twentyfour-hour mean concentration of growth hormone in peripubertal males. Journal of Clinical Endocrinology and Metabolism , 62(1): 159-164 .

[11] Leporati P., Fonte R., de Martinis L., Zambelli A., Magri F., Pavesi L., Rotondi M. et al .(2015). A male patient with acromegaly and breast cancer: Treating acromegaly to control tumor progression. $B M C$ Cancer, (15):397-401.

[12] Veldhuis J. D. , Mielke K.L., Cosma M., Soares-Welch C., Paulo R., Miles J. M. and Bowers C.Y. (2009). Aromatase and 5alpha-reductase inhibition during an exogenous testosterone clamp unveils selective sex steroid modulation of somatostatin and growth hormone secretagogue actions in healthy older men. The Journal of Clinical Endocrinology \& Metabolism, 94(3): 973-978.

[13] Selek A., Cetinarslan B., Gurbuz Y., Tarkun I., Canturk Z. and Cabuk B. (2015). Aromatase enzyme expression in acromegaly and its possible relationship with disease prognosis.Endocrine,49(1):250-257.

[14] Barrado M.J.G. , Blanco E. J., Hernandez M.C., Osma M.C.I., Carretero M., Herrero J.J., Burks D. J. et al. (2014). Local transformations of androgens into estradiol by aromatase 4450 is involved in the regulation of prolactin and the proliferation of pituitary prolactin-positive cells. PLOS ONE ,9(6): 101403101410.

[15] Adelman D.T., Liebert K.J., Nachtigall L.B., Lamerson M. and Bakker B. (2013) .Acromegaly: the disease, its impact on patients, and managing the burden of long-term treatment. The International Journal of General Medicine , (6):31-38. 

patients

[16] Bondanelli M., Ambrosio M.R., Margutti A., Franceschetti P., Zatelli M.C.and Uberti E.C. (2003). Activation of the somatotropic axis by testosterone in adult men: evidence for a role of hypothalamic growth hormone-releasing hormone. Neuroendocrinology, 77(6): 380-387.

[17] Cook D. M., Ezzat S., Katznelson L., Kleinberg D. L., Laws E. R.,NippoldtT.B., Swearingen B.et al. (2004).American Association of Clinical Endocrinologists Medical Guidelines for Clinical Practice for the Diagnosis and Treatment of Acromegaly. Endocrine Practice, 10(3):213-225 .

[18] Mitwally M.F. and Casper R.F. (2003). Aromatase inhibition reduces gonadotrophin dose required for controlled ovarian stimulation in women with unexplained infertility. Hum Reprod, 18(8):1588-97 .

[19] Rochira V., Kara E., and Carani C. (2015). The Endocrine Role of Estrogens on Human Male Skeleton.International Journal of Endocrinology ,(2015):1-15..

[20] Glubb D.M., O'Mara T.A., Shamsani J.and Spurdle A.B.(2017). The Association of CYP19A1 Variation with Circulating Estradiol and Aromatase Inhibitor Outcome: Can CYP19A1 Variants Be Used to Predict Treatment Efficacy. Front Pharmacol, 8(218):1-8.

[21] Zins K., Mogg M., Schneeberger C., Abraham D. and Schreiber M. (2014). Analysis of the rs 10046 Polymorphism of Aromatase (CYP19) in Premenopausal Onset of Human Breast Cancer. International Journal of Molecular Sciences, 15(1):712-724.

[22] Paul C.B., Sudaniradoss C.(2016). Aromatase inhibiters-types and advantages. International Journal of Pharmacy and Pharmaceutical Sciences, 8(8):1-7.

[23] Lin L., Ercan O., Raza J., Burren C. P., Creighton S. M., Auchus R. J., Dattani M.T., et al.(2007).Variable phenotypes associated with aromatase (CYP19) insufficiency in humans. The Journal of Clinical Endocrinology \& Metabolism, 92(3):982-90.

Citation: Iqbal H. Dhefer, et.al, "rs10046 Polymorphism of CYP19A1 Gene related to Sex Hormone in Female with Acromegaly Iraqi patients", International Journal of Advanced Research in Chemical Science, vol. 6, no. 12, p. 1-7, 2019. DOI: http://dx.doi.org/10.20431/2349-0403.0612001

Copyright: (C) 2019 Authors. This is an open-access article distributed under the terms of the Creative Commons Attribution License, which permits unrestricted use, distribution, and reproduction in any medium, provided the original author and source are credited. 